\title{
Butterfly-shaped Pattern Dystrophy in Myotonic Dystrophy
}

\author{
Shinji Makino, Yuko Ohkubo and Hironobu Tampo
}

Key words: myotonic dystrophy, pattern dystrophy, fundus autofluorescence

(Intern Med 51: 2253-2254, 2012)

(DOI: 10.2169/internalmedicine.51.8181)
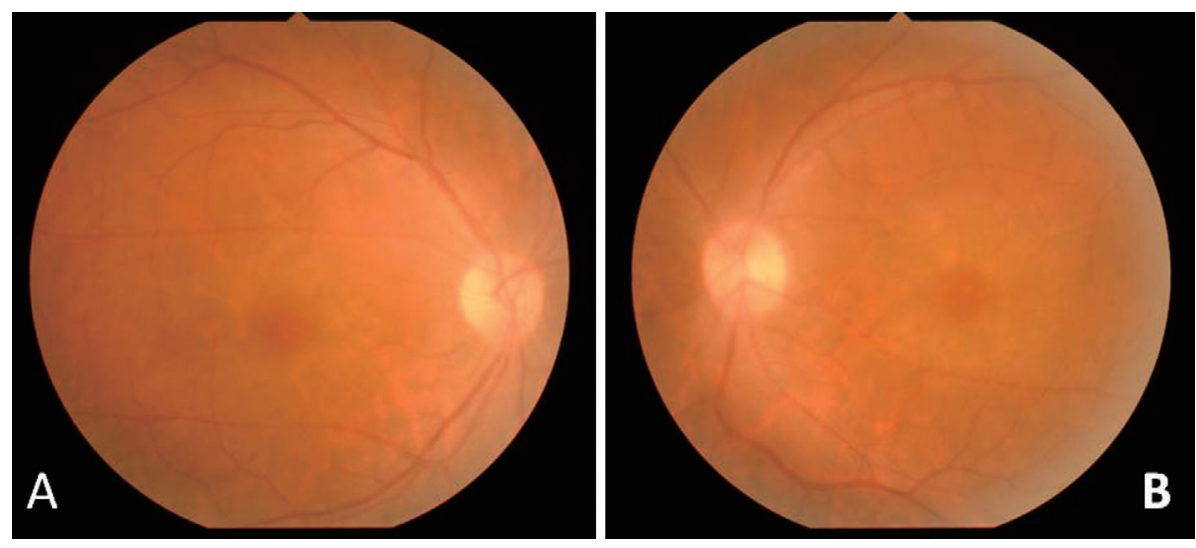

Picture 1.
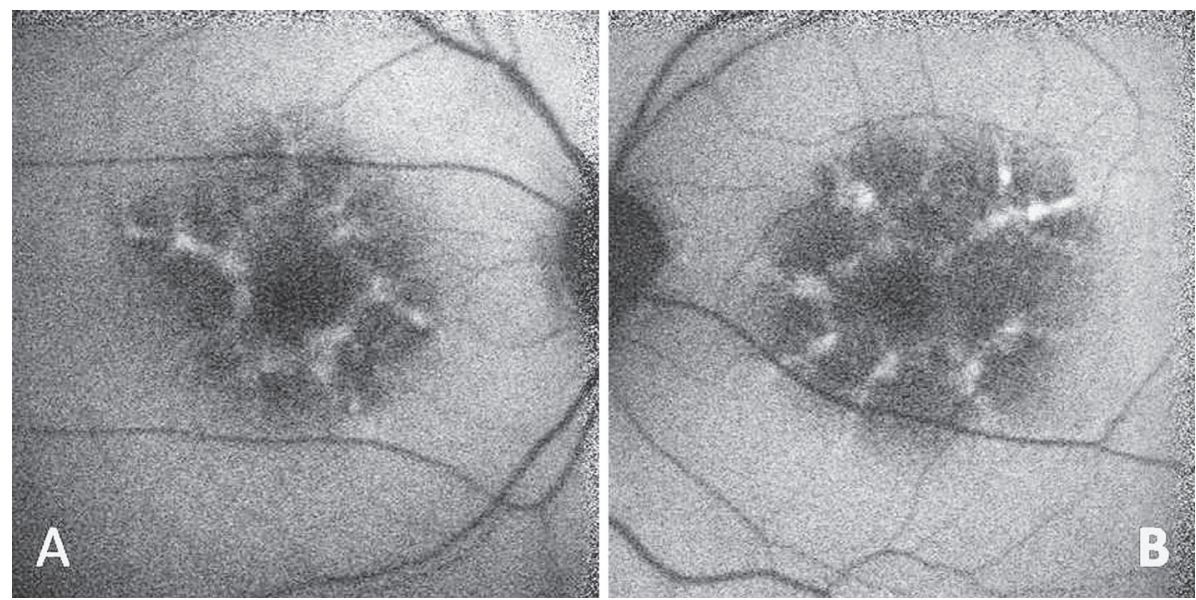

Picture 2.

A 50-year-old woman with myotonic dystrophy (MD) presented with bilateral blurred vision. Visual acuity was 16/ 20 in both eyes. Slit lamp examination showed cortical and posterior subcapsular opacities in both lenses. Funduscopy showed depigmented changes at the macula, however, details were unclear due to the presence of cataract (Picture 1).
Fundus autofluorescence (FAF) imaging clearly defined butterfly-shaped pattern dystrophy (BPD) in the hypofluorescent area corresponding to the depigmented changes (Picture 2).

Kimizuka et al. evaluated 49 patients with MD for macular changes as examined by fluorescein angiography (1); 
$26.6 \%$ showed a butterfly-shaped pattern, while $24.5 \%$ showed a reticular pattern.

BPD has been linked to various mutations in the human retinal degeneration slow $(R D S)$ /peripherin gene. In $\mathrm{MD}$, the macular changes resemble BPD. In BPD, lipofuscincontaining retinal pigment epithelium (RPE) has been reported.

FAF is a noninvasive imaging technique that enables visualization of lipofuscin in the RPE (2). Retinal changes in MD are more easily defined on FAF images than on color photographs.
The authors state that they have no Conflict of Interest (COI).

\section{References}

1. Kimizuka Y, Kiyosawa M, Tamai M, Takase S. Retinal changes in myotonic dystrophy. Clinical and follow-up evaluation. Retina 13: 129-135, 1993.

2. Boon CJF, Klevering BJ, Keunen JEE, Hoyng CB, Theelen T. Fundus autofluorescence imaging of retinal dystrophies. Vision Res 48: 2569-2577, 2008.

(C) 2012 The Japanese Society of Internal Medicine http://www.naika.or.jp/imonline/index.html 